Thành phố Hồ Chí Minh, 18(4) tr. 74-79.

4. Lê Thị Vui (2020), Dịch tễ học rối loạn phổ tự kỷ ở trẻ 18-30 tháng và rào cản tiếp cân dich vư chẩn đoán, can thiêp rồi loạn phổ tự kỷ tai Việt Nam, 2017-2019, Luấn án tiến sỹ. Đai học Y Hà Nội.

5. Gulati Sheffáli, Kaushik Jaya Shankar, Saini Lokesh, et al (2019), "Development and validation of DSM-5 based diagnostic tool for children with Autism Spectrum Disorder", PloS one, 14 (3), 14 (3), pp. 1-11

6. Hoang Van Minh, Le Thi Vui, Chu Thi Thuy Quynh, et al (2019), "Prevalence of autism spectrum disorders and their relation to selected socio-demographic factors among children aged 1830 months in northern Vietnam, 2017", International journal of mental health systems, 13 , pp. 29-29.

7. Lai M.C, Lerch J.P, Floris D.L, al et (2017), "Imaging sex/gender and autism in the brain: Etiological implications", J Neurosci Res, 95 (1-2), pp. 380-397.

8. Sularyo Titi, Endyarni Bernie, Lestari Tri, et al (2012), "Role of Denver II and Development Quotients in the management of several pediatric developmental and behavioral disorders", Paediatrica Indonesiana, 52 (1), pp. 51-56.

\title{
THỰC TRANG QUẢN LÝ ĐIỀU TRİ BỆNH NHÂN LAO/HIV TẠI TRAM Y TẾ XÃ CỦA TỈNH THÁI NGUYÊN
}

\section{TÓM TẮT}

Mục tiêu: Mô tả thực trạng quản lý điều trị bệnh nhân lao/HIV tại trạm y tế xã của tỉnh Thái Nguyên năm 2019 - 2020 và phân tích môtt số yếu tố liên quan đến kết quả điều trị bệnh nhân lao/HIV. Đối tượng và phương pháp nghiên cứu: Nghiên cứu mô tả cắt ngang trên 60 cán bộ y tế xã và 103 bệnh nhân lao/HIV được quản lý tại xã năm 2019 - 2020. Kết quả nghiên cứu: Cán bộ y tế xã ghi chép sổ sách đầy đủ thông tin cho bênh nhân lao/HIV là 98,3\%, tỉ lệ bệnh nhân được cấp phát thuốc lao theo đúng thời gian quy định (7-10 ngày/lần) là $0 \%$, tỉ lê bệnh nhân được giám sát thường xuyên tại nhà là $70,0 \%$, tỉ lệ bệnh nhân lao phổi $\mathrm{AFB}(+) / \mathrm{HIV}$ được xét nghiệm đờm lân 1, 2, 3 lần lượt là 77,8\%, 74,1\%, $66,7 \%$. Tỉ lệ điều trị thành công lao/HIV là $93,3 \%$ (AFB $(+) / H I V$ là $77,8 \%)$. Các yếu tố liên quan đến kết quả điều trị lao/HIV là tuổi, nghề nghiệp, kinh tế gia đình, điều trị phối hợp ARV và Cotrimoxazole của bệnh nhân lao/HIV.

Tư khóa: Lao/HIV, quản lý, điêu trị, Thái Nguyên.

\section{SUMMARY \\ MANAGEMENT AND TREATMENT OF TB/HIV \\ PATIENTS AT THE COMMUNE HEALTH \\ CENTER OF THAI NGUYEN PROVINCE}

Objectives: To describe the management and treatment of TB/HIV patients at the Commune Health Center in Thai Nguyen province and analysis some factors related to TB/HIV treatment outcomes. Subjects and research methods: A cross-sectional study among 60 commune health workers and 103 TB/HIV patients who were managed at the community health centers in 2019, 2020. Results: $98.3 \%$

${ }^{1}$ Bệnh viện Lao và Bệnh phổi Thái Nguyên

2Trường Đai hoc Y Dược Thái Nguyên

Chịu trách nhiệm chính: Trần Văn Tùng

Email: tungbvitn@gmail.com

Ngày nhận bài: 22.3.2021

Ngày phản biên khoa hoc: 17.5.2021

Ngày duyệt bài: 25.5.2021 commune health workers adequately recorded TB/HIV patients; the percentage of correctly providing TB/HIV drugs for patients (7-10 days/time) was $0 \%$; the percentage of regular monitoring patients at home was $70.0 \%$; patients with TB AFB $(+) / \mathrm{HIV}$, who were tested 1st, 2nd and 3th times, were $77.8 \% 74.1 \%$, $66.7 \%$, respectively. The successful treatment rate of TB/HIV patient and AFB (+)/HIV were $93.3 \%$ and $77.8 \%$, respectively. The related factors with TB/HIV treatment outcomes were age, occupation, family economics, treatment combination between ARV and Cotrimoxazole of TB/HIV patients.

Keywords: TB/HIV, Management, Treatment, Thai Nguyen.

\section{I. ĐĂT VẤN ĐỀ}

Bệnh lao là bệnh nhiễm trùng cơ hội phổ biến nhất gây tử vong ở những người nhiếm HIV. Tổ chức Y tế thế giới (WHO) ước tính năm 2019 có khoảng 10 triệu người mắc lao, trong đó 820.000 trường hợp mắc và 208.000 tử vong do đồng nhiếm lao/HIV. Việt Nam là nước có gánh nặng bệnh lao cao, đứng thứ 22 trong 30 nước có số người đồng nhiễm lao/HIV cao nhất trên thế giới. Quản lý điều trị lao cho người có HIV rất khó khăn bởi phải phối hợp nhiều loại thuốc trong điêuu trị lao, thuốc điêu trị HIV gây nhiêuu tác dụng phụ dễ dẫn tới gián đoạn điêuu trị. Hơn nữa, người nhiễm HIV tại Việt Nam chiếm tỉ lệ cao vẫn là nhóm đối tượng nghiện chích ma tuý do đó việc không tuân đúng theo sự chỉ dẫn của cán bộ y tế là rất thường xuyên [2]. Tuy nhiên, nếu quản lý điêu trị tốt đồng thời cả lao và HIV sẽ cải thiện được kết quả điều trị lao, làm giảm tỉ lệ tử vong [8]. Tỉnh Thái Nguyên có 178 xã, phường, thị trấn với nhiêu xã có lao/HIV. Vậy thực trạng quản lý điêuu trị lao/HIV tại các xã hiện nay như thế nào? Nhằm làm rõ vấn đề đó, chúng tôi tiến hành nghiên cứu: "Thực trạng 
quản lý điều trị bệnh nhân Lao/HIV tại trạm y tế xã của tỉnh Thái Nguyên", với mục tiêu: Mô tả thực trạng quản lý điêu trị bệnh nhân lao/HIV tại trạm y tế xã của tỉnh Thái Nguyên năm 2019 2020 và phân tích một số yếu tố liên quan đến kết quả điều trị bệnh nhân lao/HIV.

\section{II. ĐỐI TƯỢNG VÀ PHƯƠNG PHÁP NGHIÊN CỨU}

2.1. Đối tượng nghiên cứu: Cán bộ $Y$ tế (CBYT) phụ trách chương trình Chống lao (CTCL) và bệnh nhân lao/HIV điều trị ngoại trú tại xã, phường, thị trấn từ tháng 1/2019 - 12/2020.

2.2. Thời gian và địa điểm nghiên cứu: Từ 05/2020 đến 05/2021 tại Trạm Y tế (TYT) của tỉnh Thái Nguyên.

2.3. Phương pháp nghiên cứu: Mô tả cắt ngang.

2.4. Phương tiện nghiên cứu: Sổ sách, báo cáo quản lý bệnh nhân lao/HIV, phiếu điều tra CBYT, bệnh nhân lao/HIV.

\subsection{Các biến số nghiên cứu}

- Quản lý lao/HIV: CBYT ghi chép sổ sách đầy đủ, tần suất cấp thuốc, tần suất giám sát bệnh nhân điều trị tại nhà, xét nghiệm đờm kiểm soát, kết quả điều trị lao/HIV.

- Các yếu tố liên quan đến kết quả điều trị lao/HIV: Tuổi, giới, dân tộc, nghề nghiệp, nơi cư trú, kinh tế hộ gia đình, điều trị phối hợp ARV, Cotrimoxazol.

2.6. Tiêu chuẩn sử dụng trong nghiên cứu: Điều trị thành công là trường hợp khỏi, hoàn thành điều trị (HTĐT), điều trị không thành công là điều thất bại, chết, bỏ trị, không đánh giá được. Tiêu chuẩn đánh giá tần suất giám sát: không bao giờ: 0 lần/tháng; hiếm khi: 1 lần/tháng; thỉnh thoảng: 2 - 3 lần/tháng; thường xuyên: $\geq 4$ lần/tháng
2.7. Xử lý số liệu: Bằng phần mềm Epidata 3.1 và SPSS 18.0.

2.8. Đạo đức nghiên cứu: Đề cương nghiên cứu đã được hội đồng đạo đức, Trường Đại học Y Dược, Đại học Thái Nguyên thông qua.

\section{KẾT QUẢ NGHIÊN CứU}

Bảng 1. Cán bộ y tế xã thực hiện ghi chép số sách

\begin{tabular}{|c|c|c|}
\hline $\begin{array}{c}\text { Ghi chép số sách đâyy } \\
\text { đủ thông tin }\end{array}$ & SL & TL \% \\
\hline Có & 59 & 98,3 \\
\hline Không & 1 & 1,7 \\
\hline Tống & $\mathbf{6 0}$ & $\mathbf{1 0 0}$ \\
\hline
\end{tabular}

CBYT thực hiện ghi chép đầy thông tin là $98,3 \%$, ghi chép chưa đầy đủ là 1,7\%.

Bảng 2. Tân suất cấp phát thuốc lao cho bệnh nhân lao/HIV ở giai đoạn duy tri

\begin{tabular}{|c|c|c|}
\hline Số ngày cấp/lần & SL & TL \% \\
\hline $7-10$ ngày & 0 & 0,0 \\
\hline 15 ngày & 43 & 71,7 \\
\hline 30 ngày & 17 & 28,3 \\
\hline Tống & $\mathbf{6 0}$ & $\mathbf{1 0 0}$ \\
\hline
\end{tabular}

Tỉ lệ CBYT cấp phát thuốc từ 7-10 ngày/lần là $0 \%, 15$ ngày/lần là $71,7 \%, 30$ ngày/lần là $28,3 \%$.

Bảng 3. Tân suất giám sát bệnh nhân điều trị tại nhà của CBYT Xã

\begin{tabular}{|c|c|c|}
\hline Giám sát tại nhà & SL & TL \% \\
\hline Không bao giờ & 0 & 0 \\
\hline Hiểm khi & 2 & 3,3 \\
\hline Thỉnh thoảng & 16 & 26,7 \\
\hline Thường xuyên & 42 & 70,0 \\
\hline Tống & $\mathbf{6 0}$ & $\mathbf{1 0 0}$ \\
\hline
\end{tabular}

Tỉ lệ CBYT giám sát bênh nhân thường xuyên là $70,0 \%$, thỉnh thoảng là $26,7 \%$ và hiếm khi là $3,3 \%$

Bảng 4. Bệnh nhân lao phổi AFB (+)/HIV, AFB (-)/HIV xét nghiệm đờm kiểm soát

\begin{tabular}{|c|c|c|c|c|c|c|c|}
\hline \multirow{2}{*}{ Lần } & \multicolumn{2}{c|}{ XN đờm } & \multicolumn{2}{c|}{ Có } & \multicolumn{2}{c|}{ Không } & \multicolumn{2}{c|}{ Tống } \\
\cline { 3 - 8 } & SL & TL \% & SL & TL \% & SL & TL \% \\
\hline \multirow{3}{*}{ AFB(+) } & Lần 1 & 21 & 77,8 & 6 & 22,2 & 27 & 100 \\
\cline { 2 - 8 } & Lần 2 & 20 & 74,1 & 7 & 25,9 & 27 & 100 \\
\cline { 2 - 8 } & Lần 3 & 18 & 66,7 & 9 & 33,3 & 27 & 100 \\
\hline \multirow{2}{*}{ AFB(-) } & Lần 1 & 45 & 69,2 & 20 & 30,8 & 65 & 100 \\
\cline { 2 - 8 } & Lần 2 & 39 & 60,0 & 26 & 40,0 & 65 & 100 \\
\hline
\end{tabular}

Tỉ lệ bệnh nhân lao phối $\mathrm{AFB}(+)$ đi xét nghiệm đờm lần $1,2,3$ theo thứ tự là $77,8 \%, 74,1 \%$ và $66,7 \%$. Tỉ lệ bệnh nhân lao phổi AFB(-) đi xét nghiệm đờm lần 1,2 theo thứ tự là $69,2 \%$ và $60,0 \%$.

Bảng 5. Kềt quả điều trị của bệnh nhân lao/HIV

\begin{tabular}{|c|c|c|c|c|c|c|c|c|c|c|c|c|c|c|}
\hline \multirow{2}{*}{ Chẩn đoán } & \multicolumn{2}{|c|}{ Khỏi } & \multicolumn{2}{|c|}{ HTÐT } & \multicolumn{2}{|c|}{ Thất bại } & \multicolumn{2}{|c|}{ Chết } & \multicolumn{2}{|c|}{ Bỏ trị } & \multicolumn{2}{|c|}{$\begin{array}{l}\text { Không } \\
\text { đánh giá }\end{array}$} & \multicolumn{2}{|c|}{ Tổng } \\
\hline & SL & $\%$ & SL & $\%$ & SL & $\%$ & SL & $\%$ & SL & $\%$ & SL & $\%$ & SL & $\%$ \\
\hline Lao phối $\mathrm{AFB}(+)$ & 19 & 70,4 & 2 & 7,4 & 0 & 0 & 3 & 11,1 & 2 & 7,4 & 1 & 3,7 & 27 & 100 \\
\hline $\begin{array}{c}\text { Lao phối AFB(-), } \\
\text { lao ngoài phối }\end{array}$ & - & - & 75 & 98,7 & 0 & 0 & 1 & 1,3 & 0 & 0 & 0 & 0 & 76 & 100 \\
\hline Tống & 19 & 18,5 & 77 & 74,8 & 0 & 0 & 4 & 3,9 & 2 & 1,9 & 1 & 0,9 & 103 & 100 \\
\hline
\end{tabular}


Tỉ lệ điều trị khỏi của bệnh nhân lao/HIV là 18,5\%, HTĐT là 74,8\%. Tỉ lệ bệnh nhân chết là 3,9\%, bỏ trị là $1,9 \%$ và không đánh giá là $0,9 \%$.

Bảng 6. Liên quan giữa các đặc điểm chung của bệnh nhân lao/HIV với kêt quả điều trị lao /HIV

\begin{tabular}{|c|c|c|c|c|c|c|c|c|}
\hline \multirow{2}{*}{\multicolumn{2}{|c|}{ Đặc điểm }} & \multicolumn{2}{|c|}{$\begin{array}{l}\text { Điều trị không } \\
\text { thành công }\end{array}$} & \multicolumn{2}{|c|}{$\begin{array}{c}\text { Điêuu trị } \\
\text { thành công }\end{array}$} & \multicolumn{2}{|c|}{ Tổng } & \multirow[t]{2}{*}{$\mathbf{P}$} \\
\hline & & $\mathbf{S L}$ & TL \% & SL & TL \% & SL & TL \% & \\
\hline \multirow{2}{*}{ Tuổi } & $\geq 45$ & 6 & 14,6 & 35 & 85,4 & 41 & 100 & \multirow{2}{*}{$<0,05$} \\
\hline & $<45$ & 1 & 1,6 & 61 & 98,4 & 62 & 100 & \\
\hline \multirow{2}{*}{ Giới } & Nam & 7 & 7,5 & 86 & 92,5 & 93 & 100 & \multirow{2}{*}{$>0,05$} \\
\hline & Nũ̃ & 0 & 0 & 10 & 100 & 10 & 100 & \\
\hline \multirow{2}{*}{ Dân tộc } & Kinh & 7 & 7,2 & 90 & 92,8 & 97 & 100 & \multirow{2}{*}{$>0,05$} \\
\hline & khác & 0 & 0 & 6 & 100 & 6 & 100 & \\
\hline \multirow{2}{*}{ Nghề nghiệp } & Tự do & 6 & 18,8 & 26 & 81,2 & 32 & 100 & \multirow{2}{*}{$<0,05$} \\
\hline & Khác & 1 & 1,4 & 70 & 98,6 & 71 & 100 & \\
\hline \multirow{2}{*}{ Nơi cư trú } & Thành, thị & 3 & 11,1 & 24 & 88,9 & 27 & 100 & \multirow{2}{*}{$>0,05$} \\
\hline & Nông thôn & 4 & 5,3 & 72 & 94,7 & 76 & 100 & \\
\hline \multirow{2}{*}{$\begin{array}{l}\text { Kinh tế hộ gia } \\
\text { đình }\end{array}$} & Nghèo/cận nghèo & 6 & 17,1 & 29 & 82,9 & 35 & 100 & \multirow{2}{*}{$<0,05$} \\
\hline & Đủ ăn & 1 & 1,5 & 67 & 98,5 & 68 & 100 & \\
\hline
\end{tabular}

Có mối liên quan giữa tuổi, nghề nghiệp và kinh tế hộ gia đình với kết quả điều trị bệnh nhân lao/HIV $(p<0,05)$.

Bảng 7. Liên quan giữa điều trị phôi hợp Cotrimoxazole (CTX), ARV với kêt quả điều trị bệnh nhân lao/HIV

\begin{tabular}{|c|c|c|c|c|c|c|c|}
\hline \multirow{2}{*}{$\begin{array}{l}\text { Điêu trị } \\
\text { CTX, ARV }\end{array}$} & \multicolumn{2}{|c|}{$\begin{array}{l}\text { Đîêu trị không } \\
\text { thành công }\end{array}$} & \multicolumn{2}{|c|}{$\begin{array}{l}\text { Điều trị thành } \\
\text { công }\end{array}$} & \multicolumn{2}{|c|}{ Tổng } & \multirow{2}{*}{ p } \\
\hline & $\mathbf{S L}$ & TL \% & SL & TL \% & SL & TL \% & \\
\hline Không điêu trị CTX & 5 & 16,7 & 25 & 83,3 & 30 & 100 & \\
\hline Có điều trị CTX & 2 & 2,7 & 71 & 97,3 & 73 & 100 & $<0,05$ \\
\hline Không điều trị ARV & 4 & 44,4 & 5 & 55,6 & 9 & 100 & \\
\hline Có điều trị ARV & 3 & 3,2 & 91 & 96,8 & 94 & 100 & $<0,05$ \\
\hline Tổng & 7 & 6,8 & 96 & 93.2 & 103 & 100 & \\
\hline
\end{tabular}

Tỉ lệ điều trị thành công khi phối hợp với điều trị CTX, ARV lần lượt là 97,3\%, 96,8\%. Còn khi không phối hợp điều trị lần lượt là 83,3\%, 55,6\% với $p<0,05$.

\section{BÀN LUẬN}

* Về quản lý điều trị bệnh nhân lao/HIV.

Theo quy định giai đoạn duy trì bệnh nhân điều trị taii nhà CBYT phải giám sát thường xuyên, cấp thuốc, thăm khám, tư vấn, ghi chép đây đủ... [3]. Tuy nhiên không phải CBYT xã nào cũng thực hiện đầy đủ các quy định. Vẫn còn $1,7 \%$ CBTY xã đã ghi chép nhưng chưa đầy đủ. Kết quả của Ngô Thị Thu Tiền (2016) cũng cho thấy vẫn có $6,1 \%$ CBYT ghi chép chưa đây đủ thông tin bênh nhân vào các sổ quản lý [4].

Tỉ lệ TYT xã cấp thuốc lao cho bênh nhân lao/HIV giai đoạn duy trì 15 ngày/lân là 71,7\%; 30 ngày/lần là $28,3 \%$ và không có TYT xã nào cấp thuốc 7 - 10 ngày/lần. Kết quả này tương đồng với Ngô Thị Thu Tiền (2016) với tần suất cấp phát thuốc điều trị lao giai đoạn duy trì 15 ngày/lần và 30 ngày/lần chiếm đa số $(66,8 \%)$ [4]. Tuy nhiên, $100 \%$ bệnh nhân lao/HIV được cấp thuốc lao không đat yêu cầu của $\mathrm{CTCL}$ quốc gia (7 - 10 ngày/lần), cần khắc phục kịp thời.

Kết quả bảng 3 cho thấy $100 \%$ CBYT xã có giám sát bệnh nhân, cao hơn nghiên cứu của Ngô Thị Thu Tiền (2016) với tỉ lệ là $90,1 \%$, cao hơn Lưu Văn Bính (2012) tại Tuyên Quang cho tỉ lệ CBYT thăm bệnh nhân tại nhà là $97,45 \%$ [1], [4]. Tuy nhiên, cũng chỉ có $70 \%$ là giám sát thường xuyên.

Hoạt động xét nghiệm đờm kiểm soát trong quản lý điêu trị của bệnh lao/HIV là rất quan trọng giúp đánh giá tiến triển và kết quả điều trị [3]. Trong 27 bệnh nhân lao phổi $\mathrm{AFB}(+) / \mathrm{HIV}$, làm xét nghiệm kiểm soát lần $1,2,3$ là $77,8 \%$, $74,1 \%, 66,7 \%$ và 65 bệnh nhân lao phổi AFB (-) /HIV được xét nghiệm đờm kiểm soát lần 1,2 là $69,2 \%, 60 \%$ (bảng 4). Tỉ lệ này thấp hơn Ngô Thị Thu Tiền (2016) với tỉ lể được làm 3 lần xét nghiệm đờm kiểm soát lần lượt là: 95,3\%, 
$89,0 \%$ và $88,8 \%$ nhưng tương đồng về xu hướng là đều giảm dần từ lần 1 đến lần 3 [4].

Tỉ lệ điều trị thành công chung của bệnh nhân lao/HIV là 93,3\%. Tương đương với Saini (2016) ở Ấn Độ là 93,19\% [8], Ali (2016) ở Ethiopia 91,5\% [5]. Cao hơn Tanue (2019) ở Cameroon là 78,6\% [9]. Cao hơn Saini (2016) ở Ấn Độ 1,14\% [8]. Tỉ lệ bỏ trị trong nghiên cứu của chúng tôi là $1,9 \%$, tương đương với nghiên cứu ở Ethiopia với tỉ lệ bỏ trị là $2 \%$ [6].

*Một số yếu tố liên quan đến kết quả điều trị bệnh nhân lao/HIV. Tỉ lệ điều trị thành công bệnh nhân trên 45 tuổi là $85,4 \%$, thấp hơn dưới 45 tuổi $(98,4 \%)$ sự khác biệt có ý nghĩa với $p<0,05$. Tương đồng với nghiển cứu tai Ethiopia năm 2016 cho thấy tuổi có liên quan đáng kể đến KQĐT lao [5].

Nghiên cứu này cho thấy giới tính, dân tộc và nơi cư trú của bệnh nhân lao/HIV không có liên quan đến kết quả điều trị lao với $p>0,05$ (bảng 6). Tương đồng Tola (2019) cho rằng KQĐT không liên quan đến giới tính, nơi cư trú của bệnh nhân đồng nhiễm lao/HIV. Tuy nhiên, tác giả Tanue (2019) lại cho rằng bệnh nhân nữ có tỉ lệ điều trị thành công cao hơn so với nam giới $(82,1 \%$ và $74 \%, p=0,001)[9]$.

Có sự khác biệt về tî lệ điều trị thành công giữa các nhóm nghề, trong đó tỉ lệ điều trị thành công ở nghề nghiệp tự do là $81,2 \%$; các nhóm nghề khác là $98,6 \%(p<0,05)$. Thực tế nhóm nghề tư do thường là những người có công viêc không ổn định, nay đây mai đó dẫn tới việc cẩp phát thuốc và quản lý giám sát của CBYT không được đều đặn, thường xuyên, việc tuân thủ điều tri kém hơn các bênh nhân có công việc ổn định. Các bệnh nhân có kinh tế gia đình đủ ăn có tỉ lệ điều trị thành công là $98,5 \%$ cao hơn so với các bệnh nhân nghèo và cận nghèo $(82,9 \%)$ $(p<0,05)$ (bảng 6$)$. Tương đồng với nghiên cứu cửa Naidoo tại Nam Phi, một trong các yếu tố dẫn tới không tuân thủ điều trị phổ biến nhất ở bệnh nhân lao/HIV là nghèo đói [7].

Kết quả bảng 7 cho thây, khi điều trị phối hợp CTX và $A R V$ với điều trị lao thì $K Q Đ T$ lao của bệnh nhân sẽ có tỉ lệ điều trị thành công là $97,3 \%$ và $96,8 \%$. Cao hơn so với không điều trị phối hợp $(83,3 \%$ và $55,6 \%)(p<0,05)$. Tương đồng với nghiên cứu của Tanue (2019), cho kết quả bệnh nhân lao/HIV được điều trị kết hợp $A R V$ và $C T X$ có tỉ lê điều trị thành công cao hởn so với không được điều trị $(P<0,05)[9]$.

\section{KẾT LUÂAN}

Tỉ lệ CBYT xã thực hiện ghi chép sổ sách đây đủ thông tin là $98,3 \%$; tỉ lệ bệnh nhân được cấp phát thuốc lao theo đúng thời gian quy định (7-10 ngày/lần) là $0 \%$; tỉ lệ bệnh nhân được thường xuyên giám sát bệnh nhân tại nhà là $70,0 \%$. Tỉ lệ bệnh nhân lao phổi $\mathrm{AFB}(+) / \mathrm{HIV}$ được làm xét nghiệm đờm kiểm soát lần 1,2 và 3 lần lượt là $77,8 \%, 74,1 \%$ và $66,7 \%$. Tỉ lệ điều trị thành công lao/HIV là 93,3\%: lao phổi $\mathrm{AFB}(+) / \mathrm{HIV}$ là $77,8 \%$, lao phổi AFB(-)/HIV là 98,7\%.

Có mối liên quan giữa tuổi, nghề nghiệp, điều kiện kinh tế hộ gia đình, điều trị phối hợp CTX và ARV với kết quả điều trị lao/HIV $(p<0,05)$.

\section{TÀI LIỆU THAM KHẢO}

1. Lưu Văn Bính (2012), "Thực trạng phát hiện, quản lý điêu trị bệnh nhân lao và kểt quả tập huấn nâng cao năng lực phòng chống lao cho cán bộ y tế cơ sở tỉnh Tuyên Quang". Luận văn bác sỹ chuyên khoa cấp II, Trường Đại học Y Dược, Đại học Thái Nguyên.

2. Bộ Y tế (2020), "Báo cáo kết quả công tác phòng, chông HIV/AIDS năm 2019 và nhiệm vụ trọng tâm năm 2020". Bộ Y tễ, Hà Nội.

3. Bồ Y tế (2020), "Hướng dẫn chẩn đoán, điêuu trị và dự phòng bệnh lao". Bộ Y tế, Hà Nội.

4. Ngô Thi Thu Tiên (2016), "Thực trang phát hiện, quán lý điều trị lao tại Thái Nguyên giai đoạn 2011-2015 và đề xuất một số giải phap can thiệp". Luận văn bác sỹ chuyên khoa câp II, Trường Đại học Y Dược, Đại học Thái Nguyên.

5. Ali, Solomon Ahmed, et al. (2016), "Outcomes of TB treatment in HIV co-infected TB patients in Ethiopia: a cross-sectional analytic study", BMC infectious diseases. 16(1), pp. 640-640.

6. Belayneh, M., Giday, K., and Lemma, H. (2015), "Treatment outcome of human immunodeficiency virus and tuberculosis coinfected patients in public hospitals of eastern and southern zone of Tigray region, Ethiopia", Braz ] Infect Dis. 19(1), pp. 47-51.

7. Naidoo, Pamela, et al. (2013), "Predictors of tuberculosis (TB) and antiretroviral (ARV) medication non-adherence in public primary care patients in South Africa: a cross sectional study", BMC public health. 13, pp. 396-396.

8. Saini, Shveta, Singh, Mukhmohit, and Garg, Anil (2016), "A Retrospective Cohort Study of Treatment Outcome among HIV positive and HIV negative TB patients in Chandigarh, India", Indian Journal of Community Health. 28(2).

9. Tanue, Elvis Asangbeng, et al. (2019), "Tuberculosis treatment outcome and its associated factors among people living with HIV and AIDS in Fako Division of Cameroon", PloS one. 14(7), pp. e0218800-e0218800. 